\title{
Selective medical examinations on starting school
}

\author{
E M O'CALLAGHAN AND A F COLVER
}

Beaconhill Children's Centre, Cramlington, Tyne and Wear

SUMmaRY Selective medical examination of children starting school has been operated in Cramlington for five years, and the data for the school year 1984-85 are reported. It is argued that the 'routine medical' is an outdated concept and that its abolition would allow more time for more important aspects of educational medicine including help for adolescents, disabled children in school, and deprived children who have not received basic health surveillance.

Since 1959 there has been no statutory obligation to carry out medical inspections of children at particular ages. Many local authorities became selective in their re-examination of children between 7 and 16 years but most retained the routine medical examination at school entry. This need has now also been questioned. The Court committee stressed the importance of observation by teachers and health visitors in the assessment of a child at school entry and felt that routine medical examinations failed to identify children's current problems. ${ }^{1}$ Lowdon et al, in a study of 1255 routine school entry medical examinations, concluded that it would have been more profitable to coordinate information already available from the records of clinics and health visitors, and from class teachers, and hearing and vision screening, and thereby to select only a few children for formal examination. ${ }^{2}$ Whitmore, in a study of 351 routine school entry medical examinations, concluded that there was a strong case not only for reducing the number of school entrants examined in some areas, but also for maintaining or improving the content and quality of the examinations of those selected. ${ }^{3}$

In 1978 a system of selective school entry medical examinations was introduced in Cramlington. We describe that system, report on the data for the school year 1984-85, and discuss why we believe a selective system should be used by more health authorities.

\section{Methods}

Cramlington is a new town, started in 1965. It has a population of 26000 , of which 5000 are school children. It has a well circumscribed area in which family doctors operate from two health centres.
Most children are seen at the preschool clinics either by their family doctor or by a clinical medical officer. Doctors examined children aged 6 weeks, $2 \frac{1}{2}$ years, and 4 to $4 \frac{1}{2}$ years.

When a child starts school the parents are given a pamphlet explaining the school health service. During the first term all parents are sent a letter, which explains the system of selective school medical examinations and asks them whether they would like their child to see the school doctor.

If a child's immunisation record is unknown or not up to date the parents and the family doctor are informed. One year later the child's immunisation record on the health district computer is inspected to discover whether the omitted immunisations have been given. All children have their hearing and vision screened by technicians during their first year at school.

When the child has been in school for a term a class review is arranged between the school doctor, reception teacher, school nurse and head teacher. This review takes about 45 minutes for 30 children. The doctor brings to the review details of the preschool surveillance received by the child, and of identified medical problems. Any concern the teacher may have about a child can therefore be discussed in the light of medical information of which the school may have been unaware. Most children do not give cause for concern and the discussion can therefore concentrate on the few who do. The school then ensures that parents know of this concern and appropriate referral is made to-for example, the educational psychologist or speech therapist. Children on the non-accidental injury register are specifically discussed at the class review. Children are selected for medical examination only if there is: no preschool medical record; insuf- 
Table Reasons for selection for medical examination

\begin{tabular}{lc}
\hline Reason & $\begin{array}{l}\text { No of } \\
\text { children }\end{array}$ \\
\hline Preschool records not available & 73 \\
No documentation of height, heart, testes & 5 \\
Clarification of previously noted medical problems & 5 \\
Request by school & 7 \\
Request by parents & 5 \\
\hline Total & 95 \\
\hline
\end{tabular}

ficient detail in the record to be sure that height, heart, and testes have been checked; a need for clarification about a known medical condition or special educational need; the teacher has a worry about a child; or the parent has requested a consultation.

Between 20 and 30 minutes are allowed for each medical examination, and the results are discussed with teachers if parents are agreeable.

\section{Results}

Ten primary schools in Cramlington had 494 entrants in the school year September 1984 to August 1985 . Of these, $96(19 \%)$ were selected to be seen by the school doctor. Most had a medical examination because their preschool record was not available, and in only one was a problem identified (enuresis). Twenty two children were seen for other reasons (table). Of the seven children reviewed at the request of their school, two were seen because of poor coordination and clumsiness; one because of delayed speech; one because of small stature; one for urinary frequency; two children were seen because they had a high rate of absenteeism. Of the five children seen at their parents' request, three required reassurance, one needed treatment for enuresis, and one child did not attend.

Twelve children and their parents did not attend their first appointment, but after two further invitations only two children had not been seen and their health visitors were informed.

\section{Discussion}

This report describes one year of selective medical examinations carried out on school entry in Cramlington. The system has been running for five years, is no longer experimental, and is accepted by teachers and parents. We report it because $90 \%$ of health authorities continue to expect routine medical examinations for all children when they start school (CR Haines, personal communication) and we regard this as a poor use of time which could be better spent on other aspects of educational medicine.

The main argument against a routine system is that the organisation of medical care has changed and the important diseases which originally justified routine examinations are under control. Babies are now examined by doctors at birth; malnutrition is a rare problem; chronic infections such as tuberculosis are now uncommon; medical care is available free of charge to all preschool children and health visitors encourage the use of this service. Defects in vision and hearing are better identified by a screening service than as part of a medical examination. Educational psychologists now have the responsibility for assessing learning difficulties.

The new problems of childhood which have emerged and with which a school health service should be concerned are the effect of handicap on school life, the social, behavioural, and emotional difficulties of children, and language difficulties. These are precisely the problems which are difficult to assess at a medical examination, but which come to light at school, and which are best dealt with by close cooperation between doctors, teachers, and psychologists.

When the routine medical examination at school entry was a 'reasonable idea' and a 'reasonable use of resources', the burden of proof for its abolition rested with those who favoured such action. For the reasons already outlined, a selective system now seems to be the reasonable idea and reasonable use of resources, so the burden of proof for the retention of routine school medical examinations now rests with those who favour their retention. They must show that a routine medical examination will identify new problems which are amenable to treatment and which would not come to light in other ways. To our knowledge such proof is not available: indeed, the recent studies we know of suggest that identification of an important treatable condition at a routine medical examination is rare. A study of 124 such examinations by Polnay et al failed to identify any new conditions. ${ }^{4}$ In Newcastle 40 children not selected for a medical were later examined as part of a research project and one new abnormality (an inguinal hernia) was found. ${ }^{5}$

An argument in favour of a routine system is that a neurodevelopmental examination can be performed. This takes various forms but usually concentrates on soft neurological signs such as clumsiness, mixed laterality, and choreiform movement. Such examinations are useful for research purposes but in our view should not be routine because the range of normal is not clearly defined; there is large interobserver variation; and children with learning, 
language, and behaviour difficulties are more likely to have minor neurodevelopmental abnormalities than controls. The reverse, however, is not true. ${ }^{6}$ In addition, many minor neurodevelopmental problems improve spontaneously. ${ }^{7}$ Learning and behaviour difficulties are not helped by treatment of an associated neurodevelopmental abnormality, and there are dangers in drawing to the attention of parents and teachers a problem of uncertain prognosis and importance which is unlikely to respond to treatment.

Although our report is from a new town, the Riverside Project in Newcastle showed that a similar system is practical in a deprived inner city area and argued that a selective system is even more important in such areas. ${ }^{6}$ The need for doctors to support teachers is greater in inner cities as many parents do not attend routine medical examinations and do not see the relevance of the school health service. Resources in a selected system can be concentrated on the children who do not attend child health clinics, or about whom there is no record of screening and immunisation. These are the children about whom there should be concern.

Whether a selective system saves time depends on how many selective medical examinations are needed after the class review. In the Riverside area, where the preschool services are underdeveloped and the population is mobile, $40 \%$ of children needed to be seen at school entry. No time was saved, but the time was used more profitably. In Cramlington only about $20 \%$ of children needed to be seen, so time was saved and was therefore available for other aspects of school healthnotably, to help adolescents, disabled children in school, and deprived children who had not received basic health surveillance.

Most health authorities have already abandoned routine medical examinations after children have started school. Has not the time come for a similar change at school entry? Rather than wasting resources on routine activity, should not examination be directed to those children starting school who have not received the small number of important screening tests available and to those children about whom the teacher or parents are concerned?

We thank Dr John Tuke for many of the ideas in this article, and Mrs Joan Ryrie for preparing the manuscript and for her efficient administration of the Cramlington school health service.

\section{References}

1 Committee on Child Health Services. Fit for the future. London: HMSO, 1976. (Cmnd 6684). (Court Report).

2 Lowdon GM, Walker JH. The school health service and the school doctor: bridging in health. Oxford: Nuffield Provincial Hospitals Trust. 1975

${ }^{3}$ Whitmore $\mathrm{K}$. The past, present and future of the health services for children in school. In: Macfarlane JA, ed. Progress in child health Vol 1. London: Churchill Livingstone, 1984.

${ }^{4}$ Polnay L, Hull D. Community paediatrics. London: Churchill Livingstone, 1985:184.

5 Turner S. Riverside Child Health Project. Evaluation report. Newcastle: University of Newcastle upon Tyne, 1983.

${ }^{6}$ Kalverboer AF. A neurobehavioural study in preschool children. London: Spastics International Medical Publications, 1975: $90-4$

${ }^{7}$ Gillberg IC. Children with minor neurodevelopmental disorders. Dev Med Child Neurol 1985;27:3-16.

Correspondence to Dr A F Colver, Beaconhill Childrens Centre, Cramlington, Tyne and Wear NE23 6EH.

Received 20 May 1987 